\title{
UM NOVO PROCEDIMENTO DE SÍNTESE DA ZEÓLITA A EMPREGANDO ARGILAS NATURAIS
}

\section{Reus T. Rigo* e Sibele B. C. Pergher}

Departamento de Química, Universidade Regional Integrada do Alto Uruguai e das Missões, Campus Erechim, Av. Sete de Setembro, 1621, 99700-000 Erechim - RS, Brasil

Diego I. Petkowicz e João H. Z. dos Santos

Instituto de Química, Universidade Federal do Rio Grande do Sul, Av. Bento Gonçalves, 9500, 91501-970 Porto Alegre - RS, Brasil

Recebido em 26/9/07; aceito em 22/7/08; publicado na web em 18/12/08

\begin{abstract}
A NEW PROCEDURE FOR A ZEOLITE SYNTHESIS FROM NATURAL CLAYS. This work proposes the synthesis of zeolite A by IZA standard proceedures starting from a natural clay. The clay was used in its natural form and after calcination at $900^{\circ} \mathrm{C}$. The resulting materials were characterized by X-ray diffraction (XRD), scanning electron microscopy (SEM) and porosity analysis by nitrogen adsorption. Results showed low surface area for Na-A zeolite in sodium form, but a higher one in CaA based on the nitrogen accessibility. The presence of cubic crystals for the A phase was observed in the SEM micrographies. The new procedure starting from natural clay favors the formation of sodalite while that using the calcinated clay gives A.
\end{abstract}

Keywords: synthesis; zeolites; clays.

\section{INTRODUÇÃO}

As zeólitas são aluminossilicatos cristalinos de larga aplicação industrial. Numerosos processos industriais de refino, petroquímica e química fina utilizam catalisadores à base de zeólitas. As razões de seu êxito em catálise são sua alta área superficial, capacidade de adsorção, seus centros ácidos, o tamanho de seus canais e cavidades e sua seletividade de forma. Estas características fazem com que as zeólitas sejam materiais interessantes para serem utilizados também como trocadores iônicos, peneiras moleculares e adsorventes. ${ }^{1}$

A estrutura das zeólitas apresenta canais e cavidades interconectados ou não de dimensões moleculares, nas quais se encontram os íons de compensação, moléculas de água ou outros adsorvatos e sais. Esse tipo de estrutura microporosa confere às zeólitas uma superfície interna muito grande, quando comparada à sua superfície externa. A estrutura da zeólita permite a transferência de matéria entre os espaços intracristalinos. No entanto, essa transferência é limitada pelo diâmetro dos poros das zeólitas. Dessa forma, só podem ingressar ou sair do espaço intracristalino aquelas moléculas cujas dimensões são inferiores a certo valor crítico, que varia de uma zeólita a outra. ${ }^{2}$

A síntese tradicional de zeólitas utiliza hidrogéis como matériaprima. Novos processos de síntese de zeólitas empregando matérias-primas mais econômicas vêm sendo objeto de vários estudos. Matérias-primas naturais, tais como diatomito, perlita, ${ }^{3}$ caulim, outros argilominerais ${ }^{4}$ e cinzas de carvão, ${ }^{5,6}$ vêm sendo empregadas na síntese de zeólitas, tais como A, ${ }^{7,8} \mathrm{X},{ }^{7-15} \mathrm{HS},{ }^{7,16,17} \mathrm{ZSM}-5,{ }^{18}$ Ofretita, ${ }^{12}$ Mordenita, ${ }^{19,20}$ entre outras.

Os rendimentos das sínteses são mais baixos se comparados àqueles obtidos através da síntese tradicional, utilizando reagentes de alta pureza. Além disso, nessas rotas empregando matérias-primas naturais freqüentemente mais de uma fase está presente. Isso decorre principalmente porque o procedimento empregado na síntese de zeólitas a partir de argilas é o de fusão alcalina. Apesar desses inconvenientes, a síntese de zeólitas a partir de matérias-primas naturais continua sendo atraente devido ao baixo custo, além da possibilidade do uso

*e-mail: reusrigo@yahoo.com.br de resíduos de outros processos como matéria-prima contribuindo, desta forma, para a preservação do meio ambiente.

O objetivo deste trabalho foi investigar a viabilidade de obtenção da zeólita A, empregando um novo procedimento que, ao invés de usar a fusão alcalina, se baseia na síntese padrão da zeólita A, usando um caulim natural como fonte de silício e alumínio.

\section{Zeólita A}

A zeólita A é sintetizada normalmente na forma sódica e apresenta uma relação $\mathrm{Si} / \mathrm{Al}$ igual a 1 . Pertence ao sistema cúbico e quando está completamente hidratada e na forma sódica tem um parâmetro de célula unitária igual a 24,60 ̊̊. A fórmula química de sua célula unitária pode ser expressa como $\mathrm{Na}_{96} \mathrm{Al}_{96} \mathrm{Si}_{96} \mathrm{O}_{384} \cdot 27 \mathrm{H}_{2} \mathrm{O}{ }^{2}$

Estruturalmente, a zeólita A pertence ao grupo $\mathrm{C}_{4}-\mathrm{C}_{4}$. Sua estrutura cristalina pode ser descrita através da união de dois tipos de poliedros: um cubo simples (4-4) formado pela união de dois anéis de quatro tetraedros e, um octaedro truncado formado pela combinação de 24 tetraedros, melhor conhecido como cavidade $\beta$ ou cavidade sodalita. A união das cavidades sodalitas, por quatro de suas faces quadradas, com os anéis duplos de quatro tetraedros conduz a um poliedro, o qual encerra uma grande cavidade conhecida como "supercavidade $\alpha$ " de diâmetro interno igual a 11,4 A, acessível através de poros delimitados por 8 átomos de oxigênio de abertura livre igual a $4,2 \AA{ }^{2}$

A combinação destas supercavidades $\alpha$ entre si e com as cavidades $\beta$ origina a estrutura final da zeólita (Figura 1), a qual apresenta dois sistemas de canais tridimensionais interconectados entre si: um sistema formado pela união de supercavidades $\alpha$, que conforme anteriormente mencionado apresenta um diâmetro interno de 11,4 Å, acessível através de aberturas circulares formadas por anéis de 8 átomos de oxigênio, de diâmetro igual a 4,2 Aं; e, um sistema de canais formado pela conexão alternada de cavidades sodalitas e supercavidades $\alpha$, acessível por aberturas formadas por 6 átomos de oxigênio de diâmetro igual a 2,2 $\AA^{2}{ }^{2}$

Devido a seu diâmetro tão reduzido, esse segundo sistema de canais é inacessível a moléculas orgânicas e inorgânicas, já que as mesmas apresentam diâmetro cinético superiores a $2,5 \AA$ ․ ${ }^{2}$ Por razões 


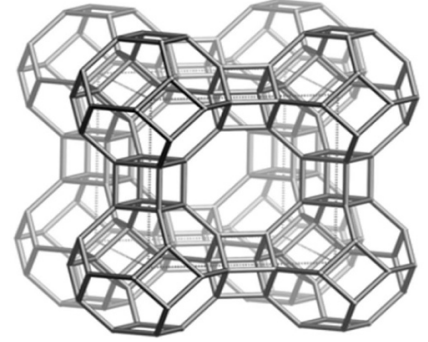

Figura 1. Estrutura da zeólita $A^{21}$

similares, o acesso ao primeiro sistema de canais (formado por anéis de 8 átomos de oxigênio) está limitado a moléculas com diâmetro cinético inferiores a $4,5 \AA ̊ 2$, tais como alcanos lineares, água, $\mathrm{CO}_{2}$, por exemplo. Cabe salientar que é devido a esse segundo sistema de canais que as zeólitas possuem grande aplicação em processos industriais, graças ao grande poder de peneiramento molecular. ${ }^{2}$

\section{PARTE EXPERIMENTAL}

\section{Síntese verificada IZA}

A síntese da zeólita A foi realizada seguindo o procedimento IZA. ${ }^{21}$ Em uma síntese típica, inicialmente prepara-se uma solução de $\mathrm{NaOH}: 80$ g de $\mathrm{H}_{2} \mathrm{O}+0,72 \mathrm{~g}$ de $\mathrm{NaOH}$. Após completa dissolução, divide-se a solução em duas frações de volumes iguais $\left(\mathrm{V}_{1} \mathrm{e} \mathrm{V}_{2}\right)$. Na primeira fração $\mathrm{V}_{1}$, adicionam-se $8,26 \mathrm{~g}$ de aluminato de sódio. $\mathrm{Na}$ segunda fração $\left(\mathrm{V}_{2}\right)$ adicionam-se os seguintes reagentes: 4,47 g SiO${ }_{2}$, $5,84 \mathrm{~g} \mathrm{NaOH}$ e 6,58 g de $\mathrm{H}_{2} \mathrm{O}$. Após a homogeneização de ambas as frações, verte-se rapidamente a fração $V_{1}$ na $V_{2}$ e mantém-se o sistema sob agitação por aproximadamente $15 \mathrm{~min}$. O gel formado é transferido para autoclaves de aço inox revestidas de Teflon de capacidade de $60 \mathrm{~mL}$. A cristalização ocorreu em modo estático ou sob agitação, a $100{ }^{\circ} \mathrm{C}$. O tempo de cristalização foi de 2 a $4 \mathrm{~h}$.

\section{Síntese empregando argilas}

O procedimento empregado foi o padrão IZA..$^{21}$ Entretanto, no lugar da $\mathrm{SiO}_{2}$ adicionou-se argila $(8,22 \mathrm{~g})$ e a quantidade de aluminato de sódio foi de $3,15 \mathrm{~g}$.

A argila empregada foi um caulim, denominado Mina, ${ }^{20,22-25}$, proveniente da Mineração Tabatinga Ltda, situada no estado do Paraná. Esta argila foi empregada em sua forma natural e após calcinação a $900{ }^{\circ} \mathrm{C}$ por $3 \mathrm{~h}$.

\section{Caracterização dos materiais}

Os materiais preparados foram caracterizados por diversas técnicas complementares: difração de raios-X, análise textural por adsorção de nitrogênio e microscopia eletrônica de varredura.

As análises de difração de raios- $X$ foram realizadas num Diffraktometer modelo D5000 (Siemens) utilizando filtro de Ni e radiação $\mathrm{Cu}-\mathrm{k} \alpha(\lambda=1,54 \AA)$.

A caracterização textural dos materiais foi realizada utilizando um Autosorb-1 da Quantachrome (Nova-2200e). Antes da análise, cerca de $100 \mathrm{mg}$ de amostra foram tratadas a vácuo, a uma temperatura de $300{ }^{\circ} \mathrm{C}$ por $3 \mathrm{~h}$. As medidas foram realizadas na temperatura do $\mathrm{N}_{2}$ líquido. Análises texturais também foram realizadas em materiais trocados com diferentes cátions para avaliar a acessibilidade da molécula de nitrogênio. Os experimentos de troca catiônica foram realizados a $80{ }^{\circ} \mathrm{C}$ por $16 \mathrm{~h}$, empregando soluções dos cloretos metálicos $\left(\mathrm{Ca}^{+2}\right.$, $\mathrm{K}^{+}, \mathrm{Mg}^{+2}$ ou $\mathrm{NH}_{4}^{+}$) em uma concentração de $0,1 \mathrm{~mol} \mathrm{~L}^{-1}$.
As análises de microscopia eletrônica de varredura foram realizadas em um microscópio MEV SSZ 550 (Shimadzu). As amostras foram previamente recobertas com um filme fino de ouro.

Análises do teor de Na das soluções metálicas após a troca catiônica foram realizadas empregando um espetrômetro de absorção atômica (AAS) Varian, modelo 550 (comprimento de onda de 330,3 $\mathrm{nm}$ ) usando uma chama de ar/acetileno como fonte de energia e lâmpada de cátodo oco.

\section{RESULTADOS E DISCUSSÃO}

\section{Síntese verificada IZA}

Inicialmente, o efeito do tempo de síntese na natureza da zeólita formada foi avaliado, empregando o procedimento padrão em modo estático e sob agitação. Os difratogramas de raios-X estão apresentados na Figura 2. A posição dos sinais obtidos foi comparada com aquelas descritas na literatura especializada (Tabela 1). ${ }^{21}$

De acordo com a Figura 2, observam-se picos bem definidos e finos indicando que as zeólitas A obtidas caracterizam-se por alta cristalinidade e pureza. Observa-se ainda que, independentemente do tempo de síntese estudado, as fases obtidas foram puras e cristalinas.

Ao compararmos as sínteses em sistema estático e sob agitação observa-se que se obtém um material mais cristalino na síntese em sistema estático, indicando que este procedimento é mais indicado.

A Tabela 2 apresenta os resultados de área superficial calculados pelo método BET. Esses valores são relativamente baixos, estando coerentes para a zeólita $\mathrm{Na}-\mathrm{A} .{ }^{1,2}$

Experimentos de troca catiônica foram realizados a $80{ }^{\circ} \mathrm{C}$ por $16 \mathrm{~h}$, empregando soluções de cloretos metálicos $\left(\mathrm{Ca}^{+2}, \mathrm{~K}^{+}, \mathrm{Mg}^{+2}\right.$ ou $\mathrm{NH}_{4}^{+}$) em uma concentração de $0,1 \mathrm{~mol} \mathrm{~L}^{-1}$. Os materiais obtidos foram analisados por adsorção de nitrogênio. Observa-se, pelos resultados de adsorção de $\mathrm{N}_{2}$ e pelo porcentual de troca catiônica (Tabela $3)$, que somente as amostras trocadas com $\mathrm{Ca}^{+2} \mathrm{e} \mathrm{Mg}^{+2}$ apresentaram acessibilidade à molécula de nitrogênio, resultando em maiores valores de área superficial que são similares a áreas superficiais encontradas para outros materiais zeolíticos. ${ }^{1,2}$

Os cátions ocupam posições específicas na estrutura zeolítica e o diâmetro efetivo do poro pode variar dependendo do tipo de cátion de compensação. De acordo com a literatura, ${ }^{1}$ se o cátion for $\mathrm{K}^{+}$, o diâmetro efetivo será de $3 \AA ̊$; se for $\mathrm{Na}^{+}$, de $4 \AA$ e se for $\mathrm{Ca}^{+2}$, de $5 \AA$, o que está de acordo com os resultados obtidos, onde os materiais trocados com $\mathrm{Ca}^{+2}$ e com $\mathrm{Mg}^{+2}$ apresentaram maior área superficial. Entretanto, amostras

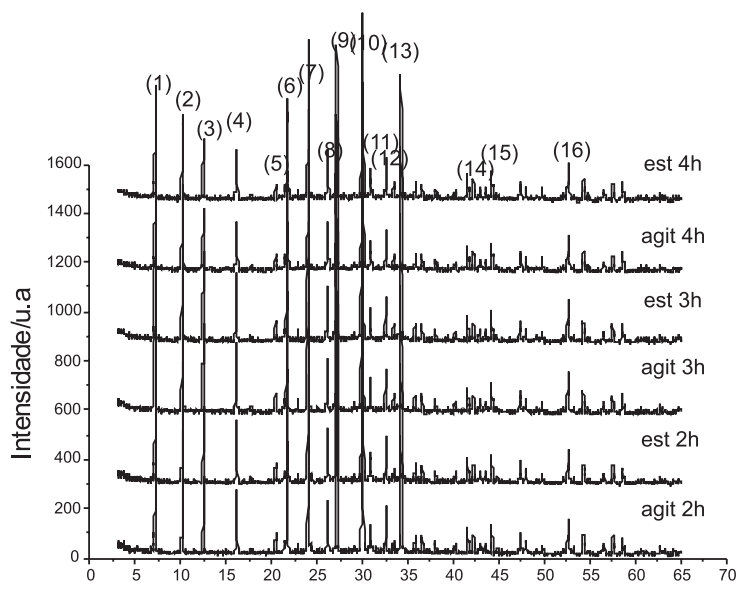

$2 \theta$

Figura 2. Difratograma de raios $X$ da zeólita $A$, síntese realizada em sistema estático e em agitação 
Tabela 1. Picos de difração dos materiais preparados pela síntese padrão IZA (estático)

\begin{tabular}{lccc}
\hline Picos* & $2 \theta$ & Int.Relat. & Ind.Miller \\
\hline 1 & 7,18 & 100,0 & 200 \\
2 & 10,17 & 54,0 & 220 \\
3 & 12,46 & 25,4 & 222 \\
4 & 16,11 & 17,8 & 420 \\
5 & 20,41 & 3,3 & 440 \\
6 & 21,67 & 16,8 & 442 \\
7 & 23,99 & 46,3 & 622 \\
8 & 26,11 & 11,3 & 640 \\
9 & 27,12 & 43,3 & 642 \\
10 & 29,94 & 24,5 & 644 \\
11 & 30,83 & 5,8 & 822 \\
12 & 32,54 & 9,4 & 840 \\
13 & 34,18 & 34,6 & 664 \\
14 & 41,52 & 6,1 & 822 \\
15 & 44,16 & 1,4 & 840 \\
16 & 47,30 & 2,0 & 886 \\
\hline
\end{tabular}

*picos assinalados na Figura 2.

Tabela 2. Valores de área superficial BET para a zeólita A

\begin{tabular}{lcc}
\hline Procedimento & Tempo $(\mathrm{h})$ & $\mathrm{BET}\left(\mathrm{m}^{2} / \mathrm{g}\right)$ \\
\hline \multirow{3}{*}{ Estático } & 2 & 5 \\
& 3 & 11 \\
& 4 & 7 \\
\multirow{2}{*}{ Agitação } & 2 & 10 \\
& 3 & 12 \\
& 4 & 12 \\
\hline
\end{tabular}

Tabela 3. Área superficial específica BET $\left(\mathrm{m}^{2} / \mathrm{g}\right)$ e entre parênteses o percentual de troca catiônica (\%)

\begin{tabular}{lccccc}
\hline $\mathrm{T}$ & $\mathrm{Na}^{+}$ & $\mathrm{Ca}^{+2}$ & $\mathrm{~K}^{+}$ & $\mathrm{H}^{+}$ & $\mathrm{Mg}^{+2}$ \\
\hline $2 \mathrm{~h}$ & 5 & $393(83,2)$ & - & - & - \\
$3 \mathrm{~h}$ & 10 & $457(86,7)$ & $5(89,8)$ & $7(90,1)$ & $503(95)$ \\
$4 \mathrm{~h}$ & 6 & $495(92,6)$ & - & - & - \\
\hline
\end{tabular}

O percentual de troca catiônica foi calculado pela diferença do teor de sódio das soluções.

trocadas com $\mathrm{H}^{+}$apresentaram baixa acessibilidade e, conseqüentemente, baixa área superficial. Análises de difração de raios $\mathrm{X}$ foram realizadas nas amostras após troca catiônica e todos os experimentos, excetuando-se a troca com $\mathrm{H}^{+}$, mantiveram a estrutura zeolítica A. Os experimentos com a troca com $\mathrm{H}^{+}$levaram ao colapso da estrutura, uma vez que se trata de material com alto teor de alumínio e zeólitas ricas em alumínio não são estáveis na forma ácida. ${ }^{2}$ A Figura 3 apresenta o difratograma obtido para as amostras trocadas.

A morfologia dos cristais da zeólita A (forma de cubos) encontrase apresentada na Figura 4, confirmando uma morfologia típica desta fase zeolítica.

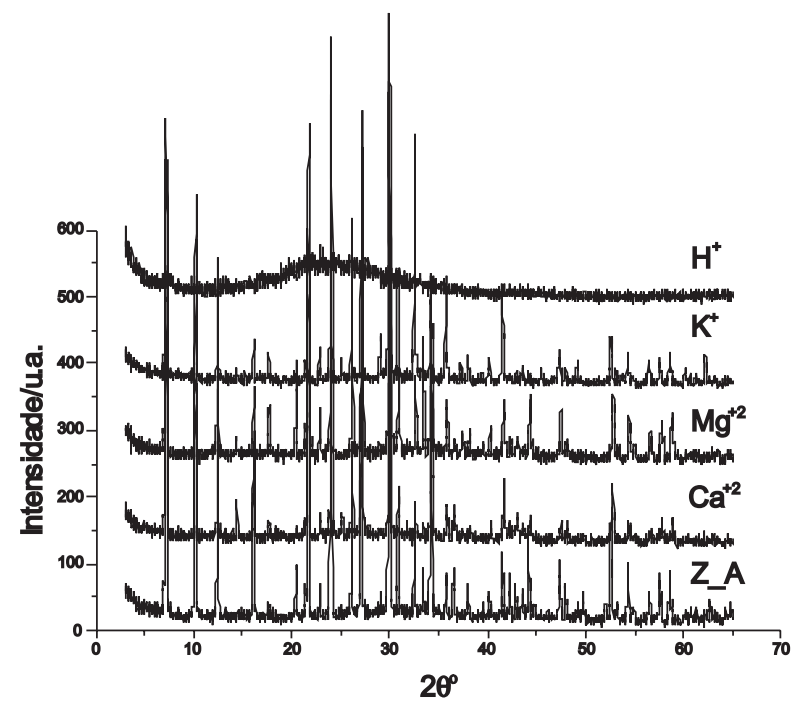

Figura 3. Difratograma de raios $X$ da Zeólita A após as trocas catiônicas

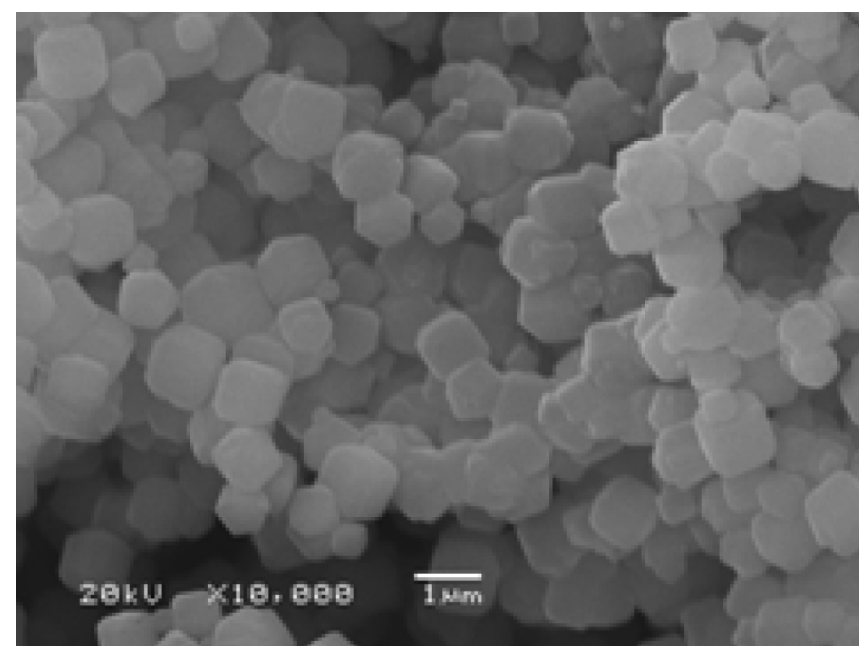

Figura 4. Microscopia eletrônica de varredura dos cristais da zeólita A

\section{Síntese empregando argila}

Os difratogramas de raios- $\mathrm{X}$ dos materiais obtidos na síntese em sistema estático empregando a argila natural (Figura 5a) apresentaram a fase zeolítica sodalita (ao comparar com padrões ${ }^{21}$ ). Observa-se também a presença de quartzo (pela presença do pico a $\sim 27^{\circ}$ ) que é proveniente da argila natural. ${ }^{22-24} \mathrm{~A}$ fase sodalita é uma fase mais estável que a fase A. Estudos anteriores ${ }^{25}$ mostraram que sínteses empregando o método de fusão alcalina em tempos iniciais obtinham a fase A e em tempos maiores ( $3-24 \mathrm{~h}$ ) se obtinha a fase sodalita. Isto está de acordo com a regra de Ostwald das transformações sucessivas. ${ }^{2}$ No caso da síntese proposta aqui, ao empregarmos a argila natural e em sistema em estático parece favorecer a formação de fases mais estáveis e mais compactas como a sodalita.

No caso do uso de argila calcinada a $900^{\circ} \mathrm{C}$, observa-se a formação da zeólita A com traços de sodalita (Figura 5b). Estes resultados demonstram que o pré-tratamento da amostra através da calcinação acima de $700{ }^{\circ} \mathrm{C}$, formando fase metacaulim por um processo de desidratação, ${ }^{26}$ conduz a fases zeolíticas mais abertas como a zeólita A. A fase metacaulim é uma fase amorfa do caulim e é considerada mais reativa. ${ }^{8}{ }^{8} \mathrm{Em}$ vista disso, podemos dizer que em temperaturas mais elevadas, como a $900{ }^{\circ} \mathrm{C}$, está ocorrendo a transformação do caulim em metacaulim, sendo esta última fase a mais adequada para 

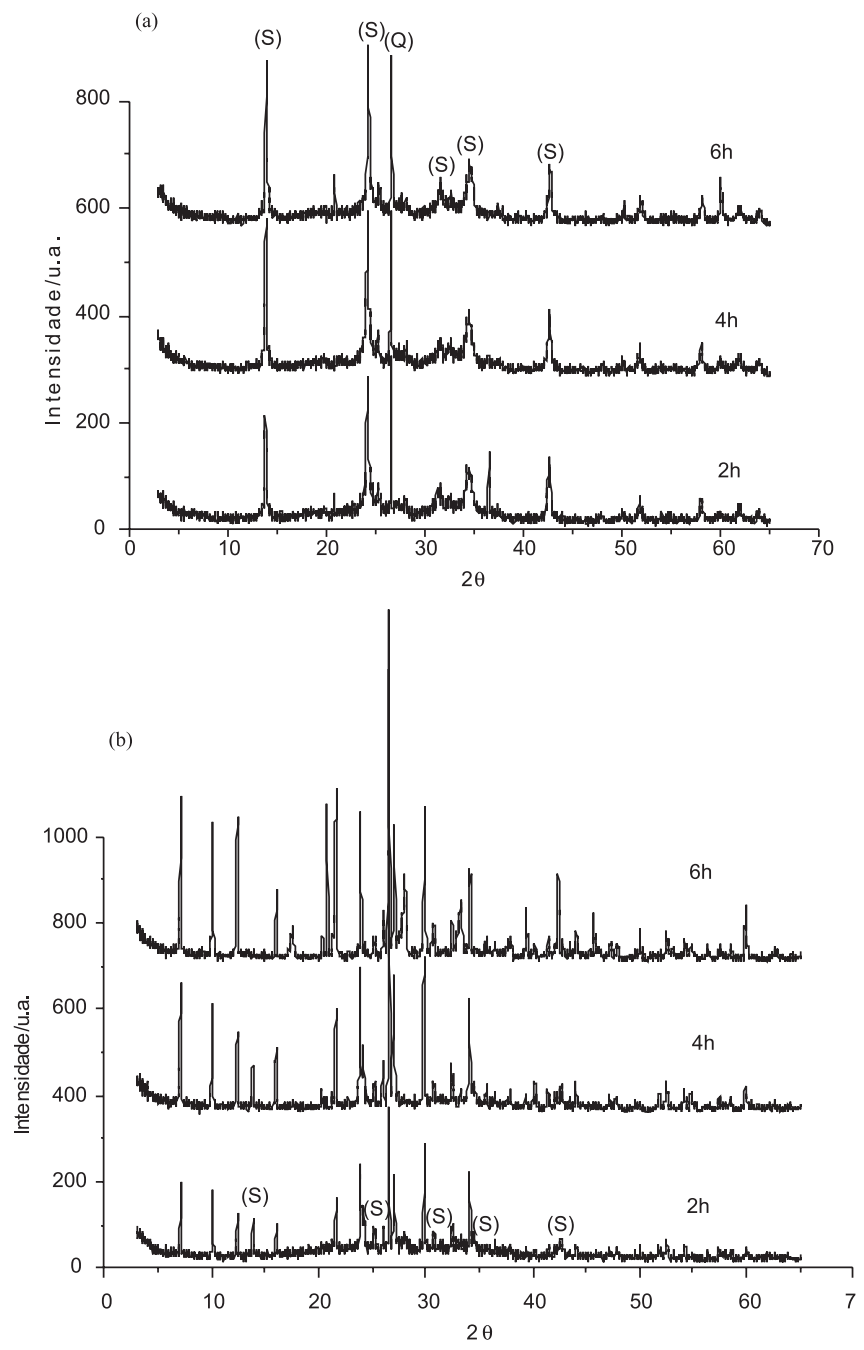

Figura 5. Difratogramas de raios $X$ da síntese realizada com argila mina natural (a) e calcinada (b)

a síntese de zeólitas, porque na desidratação ocorre a transformação de grande parte do alumínio octaédrico em tetraédrico e pentacoordenado, localizados em lâminas vizinhas a outras compostas de silício tetracoordenado. ${ }^{26}$ Além disso, a grande amorfização estrutural causada pelo aquecimento em altas temperaturas ajuda na formação da zeólita a partir do metacaulim.

As áreas superficiais obtidas empregando a argila natural apresentaram novamente valores pequenos, algumas variações podem ser devidas à contribuição da fase sodalita. Áreas superficiais maiores foram obtidas empregando argila calcinada, devido à presença da zeólita A (Tabela 4). A presença de maior teor de cátions $\mathrm{Ca}^{+2}$ que $\mathrm{Na}^{+}$na argila empregada ${ }^{20,22-25}$ favoreceu a formação das zeólitas com maior acessibilidade e, portanto, com maior área superficial.

A análise de microscopia eletrônica de varredura para as amostras obtidas a partir da argila natural apresentou a morfologia dos cristais da sodalita, ${ }^{27}$ enquanto que os materiais obtidos a partir da argila calcinada apresentaram intercrescimento de cristais cúbicos (Figura 6), típicos da fase A.

\section{CONCLUSÕES}

Zeólita A foi obtida através de uma nova rota, baseada na síntese padrão IZA, empregando argilas como fontes de silício e alumínio. A argila natural conduz à fase sodalita, enquanto que a argila calcinada
Tabela 4. Áreas superficiais BET dos materiais preparados empregando a argila

\begin{tabular}{lcc}
\hline Procedimento & Tempo (h) & BET $\left(\mathrm{m}^{2} / \mathrm{g}\right)$ \\
\hline \multirow{2}{*}{ Argila natural estático } & 2 & 36 \\
& 4 & 37 \\
\hline \multirow{2}{*}{ Argila calcinada estático } & 2 & 215 \\
& 4 & 161 \\
\hline
\end{tabular}

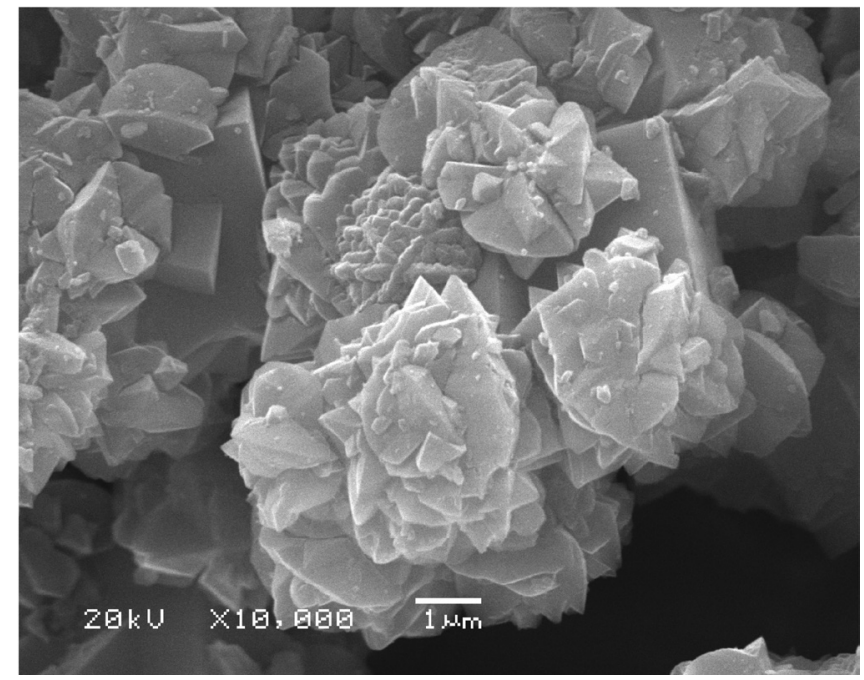

Figura 6. Micrografia da amostra sintetizada com argila calcinada

conduz à fase A. Através do procedimento proposto foi possível sintetizar a zeólita A com alta pureza a partir de argilas.

\section{AGRADECIMENTOS}

Ao CNPq pelo auxílio financeiro, à URI - Campus de Erechim pela infra-estrutura cedida para o Laboratório de Química Ambiental (LAQAM), ao Laboratório de Difração de Raios X - UFRGS pelas análises de DRX, ao Laboratório de Microscopia Eletrônica - UFRGS e à Prof. Dra. N. R. C. F. Machado, da UEM, pela amostra de argila natural.

\section{REFERÊNCIAS}

1. Xu, R.; Pang, W.; Yu, J.; Huo, Q.; Chen, J.; Chemistry of zeolite and related porous materials, Wiley - Interscience: Weinheim, 2007.

2. Giannetto, G.; Montes, A.; Rodríguez, G.; Zeolitas: Caracteristicas, Propiedades y Aplicaciones, Editorial Innovación Tecnológica: Caracas, 2000.

3. Wang, P.; Shen, B.; Gao, J.; Catal Today 2007, 125, 155.

4. Lounis, Z.; Djafri, F.; Bengueddach, A. E. K.; Ann. de Chimie-Science des Materiaux 2006, 31, 439.

5. Querol, X.; Moreno, N.; Alastuey, A.; Juan, R.; Andrés, J. M.; LopezSoler, A.; Ayora, C.; Medinacelli, A.; Valero, A.; Geol. Acta 2007, 4, 49.

6. Nugteren, H. W.; Particle \& Particle Systems Characterization 2007, 24, 49.

7. Farzaneh, F.; Oskooie, M. K.; Nejad, M. M. A.; J. Sci. Islamic Rep. Iran 1989, 1,23 .

8. Basaldella, E. I.; Kikot, A.; Pereira, E.; React. Solids 1990, 8, 169.

9. Basaldella, E. I.; Sánchez, R. T.; Vargas, S. L. P.; Resumo do XVI Simpósio Ibero Americano de Catálisis, Cartagena de Indias, Colombia, 1998. 
10. Kim, W.; Zhang, Q.; Saito, F.; J. Chem. Eng. Jpn. 2000, 33, 217.

11. Moraes, E. P.; Tese de Doutorado, Universidade Estadual de Maringá, Brasil, 2004.

12. Moraes, E. P.; Machado N. R. C. F.; Pergher, S. B. C.; Resumo do XIX Simpósio Ibero Americano de Catálise, Mérida, México, 2004.

13. Lapides, I.; Heller-Kallai, L.; Appl. Clay Sci. 2007, 35, 94.

14. Caballero, I.; Colina, F. G.; Costa, J.; Ind. Eng. Chem. Res. 2007, 46, 1029.

15. Colina, F. G.; Llorens, J.; Microporous Mesoporous Mater. 2007, 100, 302.

16. Minatelli, D. C.; Dissertação de Mestrado, Universidade de São Paulo, Brasil, 1992.

17. Shang, Y. S.; Meng, C. G.; Chem. J. Chinese Universities 2007, 28, 816.

18. Contreras, Y.; Imbert, F.; Uzcátegui, A.; Delgado, G.; Resumo do XVII Simpósio Ibero Americano de Catálise, Porto, Portugal, 2000.

19. Rodrigues, S.; Tese de Doutorado, Universidade de São Paulo, Brasil, 1984.
20. Mignoni, M. L.; Petkowicz, D. I.; Machado, N. R. C. F.; Pergher, S. B. C.; Appl. Clay Sci. 2008, 41, 99.

21. http://www.iza-online.org, acessada em Fevereiro 2007.

22. Mignoni, M. L.; Detoni, C.; Pergher, S. B. C.; Quim. Nova 2007, 30, 45.

23. Mignoni, M. L.; Petkowicz, D. I.; Machado, N. R. C. F.; Pergher, S. B. C.; Resumo do $13^{\circ}$ Congresso Brasileiro de Catálise, Foz do Iguaçú, Brasil, 2005.

24. Petkowicz, D. I.; Machado, N. R. C. F.; Sales, E. A.; Pergher, S. B. C.; Resumo do $13^{\circ}$ Congresso Brasileiro de Catálise, Foz do Iguaçú, Brasil, 2005.

25. Petkowicz, D. I.; Machado, N. R. C. F.; Sales, E. A.; Santos, J. H. Z. dos; Pergher, S. B. C.; J. Braz. Chem. Soc., submetido.

26. Akolekar, D.; Chaffee, A.; Howe, R. F.; Zeolites 1997, 19, 359.

27. Okubo, T.; Wakihara, T.; Plévert, J.; Nair, S.; Tsapatsis, M.; Ogawa, Y.; Komiyama, H.; Yoshimura, M.; Davis, M. E.; Angew. Chem., Int. Ed. 2001, 40, 1069. 